Physics for philosophers: Relativity Principle, Inertial Law and faith in what is impossible.

\title{
Física para filósofos: Principio de Relatividad, Ley de Inercia y la fe en lo imposible.
}

Jorge León de la Vega

Universidad Autónoma de Madrid leondelavega@gmail.com.

DOI: http://dx.doi.org/10.15366/bp2018.18.022

Bajo Palabra. II Época. No18. Pgs: 421-454

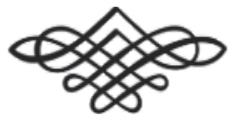


Recibido: 16/06/2016

Aprobado: 29/07/2018

\begin{abstract}
Un modo asequible de comprender por qué puede razonablemente dudarse de un aspecto concreto de la teoría geométrica de la gravitación de Albert Einstein, cuando niega el carácter de fuerza a la gravedad, es a través de la historia del Principio de Relatividad y la Ley de Inercia, desde su postulación por Galileo Galilei, su rectificación por Isaac Newton para el espacio infinito sin resistencia al movimiento, su transformación en la Teoría Especial de la Relatividad para acoger el Principio de Constancia de la velocidad de la luz, y su papel final en la Teoría General como medio de explicar la gravedad por la sola curvatura del espacio.
\end{abstract}

Keywords: gravedad, inercia, movimiento, teoría, Lógica de la Representación.

\section{Resumen}

An attainable way to understand why we must reasonably doubt about a definite aspect of Albert Einstein's geometric theory of gravitation, when he denies the character of force for gravity, is throughout the history of Relativity Principle and Inertial Law, from its postulation by Galileo Galilei, its rectification by Newton for the infinite space without resistance to movement, its transformation in the Special Theory of Relativity to receive the Constancy Principle of the Speed of Light, and its final role in the General Theory as a way to explain gravity by means of the sole curvature of space.

Palabras clave: Gravity, Inertia, Movement, Theory, Representation's Logic. 


\section{Introducción.}

EN los Últimos años han Sido fReCuentes los intentos de poner en duda algún aspecto particular de la teoría de la gravedad de Albert Einstein denominada Teoría General de la Relatividad (GTR), porque si bien es cierto que la reciente detección de ondas gravitacionales ha sido entendida un hecho sólido a favor de la teoría, al haber sido predichas por el físico hebreo-alemán, en realidad la verificación empírica únicamente conlleva la no poco importante necesidad de admitir un espacio lleno susceptible de adquirir la forma de las ondulaciones producidas por violentos fenómenos cósmicos, pero no tiene que ver, en principio, con si la mera presencia de grandes masas de materia curvan o no el espacio. Una cosa es que el movimiento provocado por una gran explosión genere ondas en el espacio, esto es, las ondas se transmiten por el éter o espacio-tiempo en vez de ser ondas puras emitidas desde la fuente surcando el espacio, y otra bien distinta que la presencia de una estrella o planeta produzca por sí misma una curvatura permanente en el espacio circundante, y que la idea se proponga de causa del movimiento orbital de los satélites. ${ }^{1}$

La principal consecuencia de la segunda hipótesis, fundamento de la GTR, implica concebir la gravedad, no en la forma de una fuerza, sino en la de un fenómeno puramente geométrico. Y la consecuencia, gravísima por su importancia, es sobre la que argumentaré serias dudas. El tratamiento del problema lo considero filosófico, lo cual no conlleva que no vayamos a tratar la cuestión desde el punto de vista físico del movimiento, y tan sólo implica el servirnos de la Lógica para proceder a mostrar lo pretendido. Lógica en su vertiente de Lógica de la Representación, o que para la representación mental del fenómeno gravitacional, según lo conocemos por experiencia y por los experimentos históricos, que la gravedad no sea una fuerza plantea una serie de problemas evidentes; fáciles de comprender si nos atenemos a los fundamentos de la Física y relegamos cuestiones anexas más complejas.

\footnotetext{
"Justo igual que identificamos como ondas de agua los pequeños rizos (ripples) que cruzan el océano, también damos el nombre de ondas gravitacionales a los pequeńos rizos a través del espacio-tiempo. ¿Rizos de qué? Rizos en la forma de la superficie del océano, rizos en la forma (i.e. curvatura) del espacio-tiempo.” Ch.W. Misner, K.S. Thorne, J.A. Wheeler. Gravitation, 943.944. Trad. propia.
} 


\section{Historia,}

NO NECESITAMOS ENTRAR EN LA PROLIFERACIÓN actual de multitud de teorías alternativas a la GTR surgidas de poner en cuestión algún aspecto concreto u otro de la teoría original de 1915, ni vamos a hacer uso de complicados cálculos matemáticos, limitando nuestro esfuerzo a explicar mediante conceptos, según es propio del filósofo, el desarrollo histórico del Principio de Relatividad y la Ley de Inercia, con el objeto de provocar en el lector la representación mental del fenómeno gravitacional según lo conocido con certeza sobre él. Nuestra base ha de resultar lo más segura e inconmovible posible, si queremos mostrar lo pretendido, y así veremos que la representación en imágenes mentales, trasladada luego en una geometría, ha sido siempre el fundamento de las dos teorías principales a confrontar en el escrito: la gravitación universal de Newton y la GTR de Einstein. Para nuestro objetivo, el lector sólo ha de tener presente desde el principio lo por todos conocido acerca del fenómeno gravitacional, manifiesto en los siguientes hechos: los planetas, estrellas y galaxias rotan sobre sí mismos; los satélites rodean sus fuentes en órbitas cuasi-circulares; y los graves se mantienen adheridos a las superficies de los cuerpos celestes o caen de inmediato hacia ellos si se sueltan desde la altura. En todos los citados fenómenos suponemos la misma causa y la llamamos gravedad, y constatamos que sigue la ley de la inversa del cuadrado con la distancia, lo que implica que el cuerpo se acelera cada vez más según va acercándose en su caída a la superficie del cuerpo celeste. De ahí el por qué la forma de la ecuación de caída de los graves: $s=1 / 2 \mathrm{~g} \mathrm{t}^{2}$, es idéntica a la de la aceleración lineal en el vacío: $s=1 / 2$ a $t^{2}$, si restamos la resistencia del aire y entendemos que g aumenta progresivamente en el movimiento de caída, según sucede con las velocidades orbitales, cada vez mayores al decrecer la distancia al centro de gravedad.

Es común a la tradición de la Historia de la Ciencia denominar a la Ley o Principio de Inercia, con cuya postulación dio comienzo la revolución científica de los siglos XVI y XVII, con el nombre genérico de Ley de Inercia Galileo-Newton, uniendo así en una única denominación lo que en verdad son dos expresiones algo diferentes, si bien compartan la definición común de movimiento uniforme:

"La revolución de la Dinámica en el siglo XVII la trajo el nuevo concepto de inercia, el movimiento rectilíneo y uniforme es un estado de un cuerpo equivalente al reposo." 2

Una definición de inercia cuya sola expresión ya contiene el Principio de Relatividad, al equiparar el movimiento relativo de los cuerpos respecto de su móvil tanto

${ }^{2}$ Crombie, A.C. Historia de la ciencia 2. De Agustín a Galileo, 125. 
en el reposo absoluto como en el movimiento uniforme a velocidad constante. Una definición cuyo origen podemos retrotraer a un siglo antes, si consideramos a Johannes Kepler el creador del concepto de materia inerte, de donde deriva la Ley de Inercia:

"Kepler introdujo el término inertia en el discurso sobre el movimiento. Pero para Kepler la inertia (del término latino que significa indolencia o indiferencia) implicaba ante todo que la materia no puede por sí misma empezar a moverse. (...) Mejor dicho, debido a su inercialidad la materia necesita un motor." ${ }^{3}$

Los conceptos de materia inerte e inercia cambian el panorama de la Física antigua griega, y son de capital importancia para obtener una idea por completo diferente del movimiento, si recordamos la inclinatio ad simile propia del Timeo de Platón como tendencia innata de los cuerpos semejantes a congregarse, o el movimiento natural aristotélico, merced al cual los cuerpos pesados tienden a caer hacia el centro de un universo esférico. Ahora, al inicio de la Edad Moderna, la materia se concibe indolente, sin tendencia natural a ir hacia lugar alguno y carente de un principio de movimiento propio. Una idea, en realidad, ya presente en cierta forma en Aristóteles, si para el filósofo griego todo cuerpo en movimiento o bien se mueve por sí mismo (semoviente) o bien es movido por otro, sin admitirse una tercera opción. ${ }^{4}$ De esta forma, lo inerte, el sujeto de la inercia, no es semoviente en el espacio sino siempre movido por otro.

Lo precedente representa no sólo la esencia del concepto de inercia, sino la definición más adecuada de materia en el sentido griego de hyle: el cuerpo físico real. Porque la introducción de la materia inerte por Kepler procede con evidencia de la observación del universo macroscópico, si bien en realidad no puede aceptarse según fue formulada, si la materia, entendida una forma de energía latente según la famosa ecuación de Einstein $\mathrm{E}=\mathrm{m} \cdot \mathrm{c}^{2}$, sí tiene principio de movimiento propio en virtud de la energía contenida en ella, pues vibra y rota a elevadas temperaturas y los fotones se mueven por sí mismos. Si bien es de la definición de materia inerte precisamente de donde ha lugar la diferencia entre materia y energía.

Galileo Galilei, en posesión del concepto de inertia de Kepler y en disposición para realizar los requeridos experimentos con planos inclinados, péndulos, el movi-

\footnotetext{
3 Bernard Cohen, I. El nacimiento de una nueva ciencia. Apéndice 8, 217.

${ }^{4}$ Excepto la mezcla de ambos, según sucede en lo biológico. En cualquier caso, lo que en ello mueve es el alma y lo movido la materia-hyle. Por eso, Aristóteles acaba por concluir en su estudio del movimiento: "todas las cosas que están en movimiento tienen que ser movidas por algo.” Física 256a 1-5. En la ontología aristotélica quienes animan la materia biológica son la naturaleza, pasando a acto la potencia inscrita en la materia, y las dos formas del alma: intelectiva y vegetativa. De ahí el papel del alma en la filosofía griega como principio de movimiento y de ahí que a los planetas se los concibiera dotados de alma y se pensara que sobre ellos actuaban inteligencias en virtud de su movimiento uniforme.
} 
miento de caída libre y el ejemplo clásico de la honda y la piedra, ofreció las primeras definiciones en orden a fundamentar la ciencia de la Física. El fundamento basilar lo encuentra en la definición matemática de movimiento uniforme y movimiento uniformemente acelerado, cuya formulación exacta debemos recordar:

"Por movimiento igual o uniforme entiendo aquel en el que los espacios recorridos por un móvil en tiempos iguales, cualesquiera que éstos sean, son iguales entre sí."

"La intensidad de la velocidad crece con el incremento del tiempo, (...) por tanto, la siguiente definición: (...) llamo movimiento uniformemente acelerado a aquel que, partiendo del reposo, adquiere en tiempos iguales, iguales incrementos de velocidad." 5

Definiciones galileanas que si pretendieran resultar aceptables hoy en día deberían haber hecho mención respecto del lugar donde se produce el movimiento, porque si en la primera, el movimiento uniforme puede producirse de dos modos diferentes: bien por una velocidad constante puramente inercial sin aceleración, bien por una aceleración constante en un medio con resistencia; el segundo modo requiere precisamente de la postulación del espacio vacío, si sólo en él es válida la definición de movimiento acelerado uniforme. Si la misma aceleración aplicada durante un lapso de tiempo en un medio con resistencia uniforme produce una velocidad constante, al igualarse aceleración y resistencia, para adquirir iguales incrementos de velocidad mediante una aceleración uniforme se precisa de un medio sin ninguna resistencia. Sólo así la ecuación que resume la ley de caída de los graves de Galileo: $s=1 / 2 \mathrm{a} \cdot \mathrm{t}^{2}$, es exacta.

No obstante, Galileo no aceptaba la existencia del espacio vacío infinito, por lo que su definición era una idealización de un proceso real, el experimentado por él dejando caer esferas bien pulimentadas por planos inclinados y desde la torre de Pisa, según cuenta lo que algunos dicen ser una leyenda. Sea como fuere, poca duda puede caber sobre que Galileo siempre se preguntaba, a la vista de los resultados obtenidos, lo que sucedería si eliminásemos la resistencia del aire o el rozamiento de la bola y la madera:

"Habiendo visto, repito, todo esto, yo llegaría a la conclusión siguiente: si se eliminara absolutamente la resistencia del medio, todos los cuerpos descenderían a la misma velocidad." ${ }^{6}$

Sentencia de donde proceden los experimentos posteriores mediante bombas de vacío para probar un hecho que al común de los mortales no le parece posible, v.g., que un cuerpo pesado y uno ligero desciendan a la vez.

5 Galileo Galilei. Consideraciones y demostraciones matemáticas sobre dos nuevas ciencias, 266 y 278.

6 Ibid, 161. 
La explicación galileana de la gravedad viene poco después:

"Un cuerpo pesado tiene, por naturaleza, un principio intrínseco que lo mueve hacia el centro común de los graves, esto es, hacia el centro mismo de nuestro globo terrestre, con movimiento continuamente acelerado y siempre igualmente acelerado." 7

De la formulación se sigue la presencia aún en Galileo de cierta tendencia natural intrinseca hacia el centro para explicar la gravedad, lo que le cierra el paso a formular un verdadero principio de inercia rectilínea. La circunstancia se aprecia bien en el concepto de impeto manejado por el físico italiano, referido en el texto siguiente al caso de impulsar un cuerpo hacia arriba que luego cae, pero también aplicable a la honda y la piedra: "Al ir disminuyendo este impeto sobreañadido y comenzar, consecuentemente, a tomar ventaja la gravitá, empieza la caída con lentitud a causa de la virtú que traía impresa el móvil y buena parte de la cual permanece todavía en él.” ${ }^{8}$

La inercia la concibe, por tanto, en la forma de fuerza (virtú) impresa en el móvil acelerado, cuando el impulso inicial dejó de ser ejercido. Si le unimos la negación del espacio vacío infinito, se ve que la inercia galileana no es estrictamente la inercia de Newton, según ahora veremos, aun si el físico inglés utilizara para explicarla un concepto parecido a la virtú galileana con la llamada Vis inertiae, y aun si en Newton la gravedad pase a ser una fuerza externa al grave cayente y no algo intrínseco.

Movimiento inercial es, en consecuencia, el adquirido por el móvil una vez que una primera aceleración provocada sobre él deja de ser ejercida. Y de ahí deriva el Principio de Relatividad de Galileo en su presentación en los Diálogos:

Encerraos con algún amigo en la mayor estancia que esté bajo cubierta de algún gran navío, y meted en ella moscas, mariposas y animalillos voladores parecidos. Haya también un recipiente de agua con pececillos dentro. Además, manténgase en alto un cubo que gota a gota vaya dejando caer el agua en otro recipiente de boca estrecha, situado abajo. Cuando la nave está quieta, observad atentamente que los animalillos volantes se mueven en todas las direcciones de la estancia con igual velocidad y los peces nadan indistintamente hacia todos lados. Las gotas de agua entrarán todas en la vasija situada debajo... Haced mover la nave con la velocidad que sea. Veréis que con tal que el movimiento sea uniforme y no fluctuante hacia aquí o hacia allá, no observaréis el más mínimo cambio en ninguno de los efectos mencionados y cómo, a partir de ellos, no podréis determinar si la nave avanza o está quieta. ${ }^{9}$

Y la razón del comportamiento previsto es, según Galileo, la acción de la parte trasera de la cabina que empuja el aire interior donde todos los objetos y animalillos

\footnotetext{
Ibid, 164 .

8 Ibid, 282.

9 Galileo Galilei. Diálogo sobre los dos máximos sistema del mundo, 162-163.
} 
han sido colocados. De esta forma, las mariposas vuelan respecto del aire interior en movimiento y el llevarse consigo el aire de la cabina mantiene también, al parecer, al cubo y la vasija en su lugar. Del experimento descrito derivan los actualmente llamados espacios galileanos, cuya principal característica radica en concebirse el espacio interno acotado en movimiento sin relación alguna con un posible espacio continente, con el cual compartiría puntos fijos inmóviles de referencia.

Así, Roger Penrose, tras citar el mismo texto, nos dice:

"No hay nada que distinga la física del estado de reposo de la del movimiento uniforme, (...) lo que esto nos dice es que no tiene significado dinámico decir que un punto particular del espacio es, o no es, el mismo punto que un punto escogido en el espacio en el instante posterior. (...) No hay un espacio de fondo (...) que permanece fijo mientras el tiempo pasa. (...) En la dinámica galileana (...) tenemos un espacio cúbico diferente para cada instante de tiempo, sin ninguna identificación natural entre estos diversos $E^{3}$. (...) A cada suceso espaciotemporal se le asigna de forma natural un tiempo, (...) pero no hay ninguna asignación natural de una localización espacial.” 10

No sé si sorprendería o no a Galileo saber que de su expresión del Principio de Relatividad hubieran derivado los espacios fibrados. En realidad, si se le pudiera preguntar, yo creo que Galileo diría que él no quiso significar estrictamente esta idea posterior plenamente relativista: la inexistencia de un espacio común a la atmósfera y a la cabina del navío, porque él debía saber que en la formulación de su experimento se obviaba un detalle importante, a saber: si el barco está primero quieto y luego adquiere una velocidad uniforme, habremos olvidado el paso de hacerlo acelerar hasta adquirirla, y la aceleración impulsora del navío, si es fuerte, haría que al menos la vasija en el suelo no mantuviera su posición inicial. Siendo el hecho también un movimiento inercial, cuyo significado con evidencia implica la pertenencia del espacio interior de la cabina al espacio exterior.

Es algo por todos experimentado, si nos introducimos en un vagón de tren, que ante el primer impulso hacia delante de la máquina nosotros nos vemos relegados hacia atrás, y si la aceleración es rápida iríamos a chocar con la pared posterior del vagón si no nos agarramos o caemos antes. El movimiento recién descrito es inercial e implica expresamente que al acelerar el tren pero no al sujeto en su interior, el último pretende permanecer en el lugar del espacio común donde se encontraba. De ahí se sigue que el experimento del barco de Galileo no conlleva lo pretendido por Penrose, sino más bien al contrario: el movimiento inercial en la aceleración muestra la existencia de un espacio común a la cabina del navío y a la atmósfera de la Tierra. Un espacio que no es empujado por la parte posterior del barco. Igual que la gravedad,

${ }^{10}$ Penrose, R. El camino a la realidad, 528-531. 
el espacio común no conoce muros y lo atraviesa y subyace a todo sin impedimentos. De ahí la difícil idea de atravesar un espacio, en el sentido precisamente de no moverlo al surcarlo, porque el espacio no es un cuerpo y al movernos se ha de filtrar entre los intersticios de los cuerpos. De ahí también que siempre haya movimiento respecto al espacio común.

No obstante, al no admitir el vacío ni el movimiento en línea recta al infinito, la Ley de Inercia de Galileo y su Principio de Relatividad, no son los de Newton. Un Principio de Relatividad cuya formulación en el ejemplo del barco ya incluye su verdadero sentido, a saber: las leyes de la Naturaleza, si el estado de reposo y el de movimiento uniforme son idénticos, deben ser las mismas para ambos observadores.

Llegamos así a la teoría de Isaac Newton, con el objeto de apreciar la diferencia entre sus Principios de Inercia y de Relatividad con los de Galileo. La Ley de Inercia de Newton es en realidad la primera Ley del Movimiento en su sistema:

"Todo cuerpo persevera en su estado de reposo o movimiento uniforme y rectilíneo a no ser en tanto sea obligado por fuerzas impresas a cambiar de estado." ${ }^{11}$

Una Ley de Inercia, en el universo newtoniano, en dependencia directa del concepto de reposo absoluto en el espacio infinito inmóvil, según se sigue de su explicación del fenómeno gravitacional:

Una piedra volteada en una honda intenta escapar de la mano del hondero y su intento hace estirarse la honda y más cuanto más rápidamente gira, y en cuanto se suelta se aleja. Llamo centrípeta a la fuerza contraria al mencionado intento; por ella, la honda retiene constantemente la piedra hacia la mano y la mantiene en el círculo y, por tanto, se dirige hacia la mano o hacia el centro del círculo. Igual ocurre con todos los cuerpos que giran en círculo. Todos intentan alejarse del centro y a no ser por una fuerza contraria a este intento, que los cohiba y los obligue en sus órbitas, y a la que por ello llamo centrípeta, se alejarían todos en línea recta con movimientos uniformes. ${ }^{12}$

Luego aquí tenemos descrito el movimiento inercial en línea recta al infinito una vez la aceleración inicial dejó de ser ejercida. A su expresión le sigue la explicación del Principio de Relatividad, donde Newton acude a un experimento cotidiano, según pudiera serlo el del barco de Galileo, y explica el igual comportamiento de los objetos en el reposo y en el movimiento uniforme por una igualdad de fuerzas contrarias:

Los movimientos entre sí de los cuerpos incluidos en un determinado espacio son los mismos, ya esté dicho espacio en reposo, ya se mueva recta y uniformemente sin movimiento

\footnotetext{
${ }_{11}$ Newton, I. Principios matemáticos de la filosofía natural, 135.

12 Ibid, 123-124.
} 
circular. Pues las fuerzas de los movimientos tendentes a un lado y las sumas de las tendentes al lado contrario, son las mismas desde el principio en ambos casos, por hipótesis,... Por tanto, en virtud de la Ley II serán iguales los efectos de los choques en ambos casos y, por ello, los movimientos de los cuerpos permanecerán iguales entre sí en un caso a los movimientos entre sí del otro. ${ }^{13}$

En puridad, la explicación del movimiento inercial en la teoría newtoniana se debe a la existencia de un espacio sin resistencia, donde los cuerpos, una vez desligados de la fuerza que los impelía, continúan con la velocidad adquirida de modo uniforme y en línea recta al infinito. Si bien sea interesante que Newton acuda a un equilibrio de fuerzas para explicar el Principio de Relatividad, por el cual la situación en el estado de reposo y en el de movimiento uniforme es la misma. La explicación, calificada por su autor de hipótesis, sólo puede entenderse si ya sabemos que en el movimiento acelerado los cuerpos en el interior de un espacio tienden a quedarse atrás y en la frenada tienden a irse hacia delante, de modo que a velocidad constante, por ese equilibrio de fuerzas, permanecen igual que en reposo.

El hecho de este tipo de explicación es debido seguramente a la pretensión propia de Newton de deducirlo todo por medio de fuerzas. Así, también el movimiento inercial puro en línea recta lo explica por medio del concepto de Vis inertiae (fuerza de inercia):

La Vis inertiae es un principio pasivo gracias al cual los cuerpos persisten en su movimiento o reposo, reciben movimiento en proporción a la fuerza que lo imprime y resisten tanto como son resistidos. Con este principio sólo, nunca habría movimiento en el mundo. Se requiere otro principio que ponga los cuerpos en movimiento y, una vez en movimiento, otro principio es necesario para conservar el movimiento. ${ }^{14}$

Con seguridad Newton no recibiría muy bien, debido a su carácter y su loable convicción de ser totalmente coherente al presentar su teoría, si le dijésemos que en realidad no necesitaba mentar el nombre de fuerza (vis) para explicar el movimiento inercial y el Principio de Relatividad, porque si en el reposo absoluto en el espacio inmóvil no actúa con evidencia fuerza alguna, tampoco necesitamos explicar el igual comportamiento de los objetos en el interior de un espacio acotado en reposo y a velocidad constante por medio de fuerzas, pues los movimientos hacia atrás y hacia delante durante los procesos de aceleración y frenado se explican por el reposo absoluto, y no el reposo absoluto por un equilibrio de fuerzas.

\footnotetext{
13 Ibid, 144-145.

${ }_{14}$ Newton, I. Óptica, 343.
} 
En Física clásica newtoniana existe un sistema de coordenadas privilegiado en reposo absoluto respecto al espacio inmóvil. En el sistema privilegiado se observarían los fenómenos naturales tal y como acontecen realmente respecto al espacio absoluto. El Principio de Relatividad de Newton lo que hace es extender la equivalencia de las leyes naturales para observadores en movimiento inercial respecto del primero en reposo en el espacio. Y lo puede hacer porque un observador en una habitación en reposo absoluto mediría las verdaderas velocidades de los cuerpos respecto al espacio inmóvil, si al permanecer él también inmóvil, las velocidades respecto de su posición son las mismas que respecto al espacio. El observador en reposo absoluto puede moverse en el interior de su habitación o sobre el cuerpo donde se encuentra con plena libertad, si carece de gravedad, y su movimiento respecto de su sistema de referencia será también un movimiento absoluto respecto al espacio inmóvil, donde se encuentra su sistema de referencia en reposo. El Principio de Relatividad extiende la misma situación a un cuerpo con velocidad inercial en base a las leyes del movimiento uniforme.

El movimiento uniforme, por tanto, se define por ser un movimiento inercial puro respecto a un espacio homogéneo e inmóvil, o también en la forma de un movimiento acelerado uniforme respecto de un espacio con resistencia. De este modo, el movimiento uniforme lo es siempre a velocidad constante sobre distancias homogéneas. Si en el vacío un cuerpo en reposo absoluto es empujado o acelerado de manera que empiece a moverse, entonces en cuanto la fuerza de impulsión cesa, el móvil se mantendrá en línea recta con la velocidad constante adquirida justo en el último momento cuando la fuerza dejó de ser ejercida. En el vacío no hay resistencia al movimiento y, en consecuencia, el móvil acelerado adquirirá un movimiento uniforme a velocidad constante una vez ya no actúe ninguna fuerza sobre él, y proseguirá en su estado de movimiento hasta el infinito si ningún otro acto se lo impide.

Al principio, si la aceleración es provocada sobre la nave con un espacio acotado interno pero no sobre los objetos en su interior, éstos tenderán a ir hacia atrás y a chocar con la pared de popa de la nave. La pared los empujará hacia delante hasta impartirles la velocidad con la que la nave se mueve. Cuando la fuerza de aceleración deje de ser ejercida, la nave mantendrá la velocidad uniforme adquirida justo hasta el momento en que la aceleración cesó y, en ese preciso instante, los objetos en su interior también habrán conseguido la misma velocidad respecto al espacio, procurada por el empuje de la pared contra ellos. Es, entonces, la igual velocidad de la nave y la de los cuerpos dentro de ella lo que produce el efecto deseado, y los pasajeros podrán moverse en su interior cual si estuviera en reposo absoluto. Ninguna fuerza de inercia es necesaria, sólo la presencia de un espacio común sin la más mínima resistencia al movimiento, a cuyo través la nave y sus pasajeros avanzan en línea recta al infinito. 
Y la anterior es la descripción de la Ley de Inercia en un espacio tridimensional euclídeo sin resistencia al movimiento. Y la referencia al infinito vacio, donde los cuerpos se sustentan pénsiles a pesar de no haber nada que los retenga en su lugar, al resultar todas las direcciones iguales y no darse preferencia por una u otra para iniciar el movimiento si no hay fuerza impelente para dirigirlo, es fundamental si queremos ver al cuerpo realmente moviéndose en línea recta a velocidad uniforme o en reposo absoluto, sin vernos obligados a admitir algo que lo sujete en su sitio; algo convertido con necesidad en resistencia cuando el cuerpo pretenda empezar a moverse.

Si hemos apreciado, en la primera explicación de la teoría ofrecida por Newton mediante el ejemplo de la honda, que la gravedad la concibe una fuerza centripeta ejercida desde la fuente con el efecto de producir una aceleración en dirección hacia el centro de la esfera, los grados de aceleración crecientes siguen la ley de la inversa del cuadrado de los tiempos con la distancia, de forma que la aceleración variará en cada punto orbital y no sucederá que el cuerpo cayente descienda, según escuchamos a Galileo, "siempre igualmente acelerado", sino que la aceleración va aumentando según el cuerpo en su caída se acerca a la fuente de gravitación. Un aumento de la aceleración inapreciable para Galileo en las pequeñas distancias en las que él se manejaba con los relojes de los que disponía.

Veremos cómo el mismo hecho parece hacer inexplicable igual proceso en la Relatividad General, si en la teoría tampoco hay lugar para la aceleración gravitacional.

Newton deduce la ecuación de la aceleración centrípeta: $\mathrm{g}=\mathrm{V}^{2} / \mathrm{S}$, y la fórmula le muestra que la ley de la inversa del cuadrado se debe a ese decrecimiento de la fuerza de gravedad y de la aceleración g con la distancia. Por eso, él dice que si esta fuerza fuese algo mayor o algo menor en cada punto orbital no podría apartar o apartaría demasiado la Luna de su curso rectilíneo. ${ }^{15} \mathrm{O}$ de otra forma, la teoría newtoniana explica así por qué cada satélite en cada órbita ha de llevar una precisa velocidad, si en cada círculo orbital actúa la aceleración adecuada para, mediante impulsos infinitesimales, impedir que el cuerpo se salga con movimiento inercial, manteniéndolo girando en elipse. Sólo, entonces, la posterior hipótesis de la nebulosa en rotación de Kant nos da la razón de por qué los satélites orbitan alrededor de sus centros.

En cuanto al Principio de Relatividad, debe recordarse el papel en física clásica del teorema de adición de velocidades. Si las leyes de la Naturaleza han de ser las mismas para un observador en reposo absoluto y para otro en movimiento uniforme,

15 Newton, I. Principios matemáticos de la filosofía natural, 124. 
el observador a velocidad constante respecto al espacio inmóvil sólo debe sumar o restar su propia velocidad a la del fenómeno observado, i.e., un haz de luz, según se dirija hacia él o siga su misma dirección. Si hace la operación el resultado habría de ser la verdadera velocidad de la luz respecto al espacio inmóvil. El intento sólo tiene el problema de conocer cuál es nuestra velocidad absoluta respecto al espacio, al no darse puntos de referencia para medirlo, pero teóricamente, si la velocidad de la luz respecto al espacio fuese constante, lo podría hacer, teniendo también en cuenta que la luz puede viajar a diferentes velocidades en la teoría clásica, según si es emitida por una fuente en reposo o en movimiento directo o contrario a la dirección del haz emitido; un hecho en relación directa con el teorema de adición de velocidades. Así, se suponía que si una estrella viaja en una dirección a determinada velocidad, a la velocidad del haz emitido por ella habría de sumársele la velocidad de la estrella.

En el punto precedente es donde interviene la primera exposición de la Teoría Especial de la Relatividad (STR) de Albert Einstein, presentada en el archiconocido artículo de 1905. Una teoría surgida con necesidad del experimento de Michelson-Morley de 1891-97, a pesar de algunas afirmaciones posteriores de Einstein al respecto, al estar los experimentos de finales del XIX pensados precisamente para calcular la velocidad absoluta de la Tierra por las variaciones en la medida de la velocidad de la luz. Al intentarlo se constató, para sorpresa de todos, que la velocidad de la luz medida en diferentes direcciones siempre era la misma, la velocidad $\mathrm{c}=$ $299.792 \mathrm{~km} / \mathrm{s}$.

Uno de los primeros en ofrecer una explicación del experimento fue H.A. Lorentz, quien propuso que el brazo del interferómetro en la dirección del movimiento terrestre se contraía en una medida equivalente a la diferencia entre la velocidad de la Tierra y la velocidad de la luz. Para ajustar su hipótesis a las ecuaciones de transformación, supuso también por hipótesis unos tiempos locales ficticios, de modo que los resultados de la transformación exigidos por el Principio de Relatividad resultasen correctos. ${ }^{16}$

En esencia, por tanto, lo que hizo Einstein fue aceptar la explicación de Lorentz, pero otorgando un significado real también a la dilatación o contracción de tiempos, convirtiendo lo ficticio en real y prediciendo con gran audacia que a los relojes naturales, y a todo proceso físico y biológico, les afecta la velocidad de su movimiento propio. La predicción de Einstein, comprobada bastante después, supone el mayor mérito indudable de la STR, junto con su famosa ecuación que relaciona la energía de un cuerpo y su masa a través de la velocidad de la luz al cuadrado.

\footnotetext{
${ }^{16}$ Ver al respecto Galison, P.L. Relojes de Einstein. Mapas de Poincaré, 226-228. Cabe recordar que en la actualidad la contracción de la longitud de los objetos en movimiento se considera aparente y recíproca en virtud del efecto del movimiento relativo entre el objeto medido y el observador.
} 
El Principio de Relatividad adquiere con ello un nuevo objetivo, al transformarse en el problema de explicar por qué todos los observadores miden la misma velocidad de la luz; algo imposible en la teoría newtoniana sujeta al teorema de adición de velocidades.

En consecuencia, el problema inicial de la ciencia física se constituye al buscar hacer compatibles dos postulados en apariencia contradictorios, desde el momento en que el Principio de Constancia de la velocidad de la luz se convierte en fundamento: si todos los observadores, sea cual sea su estado de movimiento, miden la misma velocidad c con sus respectivos interferómetros, se deduce no sólo que el teorema de adición de velocidades ha de ser sustituido por las ecuaciones de transformación de Lorentz, sino también que la velocidad de los fotones emitidos por las estrellas no puede depender del estado de movimiento del cuerpo emisor. Según lo describe Einstein en 1905:

Las mismas leyes de la electrodinámica y de la óptica serán válidas para todos los sistemas de coordenadas en los que rigen las ecuaciones de la mecánica... Elevaremos esta conjetura, cuyo contenido será denominado en adelante «el principio de relatividad», al estatus de un postulado e introduciremos también otro postulado, que es sólo aparentemente incompatible con él, a saber, la luz se propaga siempre en el espacio vacío con una velocidad definida $\mathrm{V}(\mathrm{c})$ que es independiente del estado de movimiento del cuerpo emisor. ${ }^{17}$

Aun si Einstein dudó cierto tiempo sobre la forma teórica del Principio de Constancia, ${ }^{18}$ finalmente se decidió por la citada formulación, cuya expresión se opone directamente a la teoría de la emisión defendida por otros físicos. En la teoría de la emisión de la luz, la velocidad de los fotones habría de depender del estado de movimiento de la fuente, según lo requería la teoría clásica. La formulación de Einstein niega lo precedente, a pesar de poder explicarse así el resultado negativo del experimento de Michelson y Morley. ${ }^{19}$

Además, interviene otro de los grandes descubrimientos de la época: la explicación del movimiento rapidísimo de los fotones por la interposición de sus campos eléctrico y magnético, de forma que no se necesitaba un medio subyacente para su propagación, si se entendía el movimiento de la luz en la forma de un aporte discreto de aceleración constante de un proceso sobre otro: electricidad y magnetismo y viceversa, en sucesión ininterrumpida. Era una idea contraria a la necesaria presen-

\footnotetext{
${ }_{17}$ Einstein, A. Sobre la electrodinámica de los cuerpos en movimiento, 12. De la edición Hawking.

${ }_{18}$ Ver al respecto Stachel, J. 1905: Un ańo milagroso, 103-104.

19 En el experimento se medía la velocidad de la luz emitida por una lámpara solidaria con la velocidad de la Tierra, por lo que si se sostiene la teoría de la emisión, la luz habría de tardar menos por el brazo del interferómetro en la dirección del movimiento terrestre, a pesar de resultar su trayecto algo más largo.
} 
cia en la teoría entonces en boga de un medio subyacente interpuesto denominado éter para facilitar el movimiento ondulatorio de la luz, según parecía seguirse de la teoría electromagnética de J.C. Maxwell. El hecho parecía implicar, para la mente del joven Einstein, que parecía posible prescindir del concepto de espacio y elaborar así una física puramente relativista donde no se tuvieran en consideración los movimientos absolutos. Si bien el paso no se da en la STR y habrá de esperar a la GTR donde se da la explicación geométrica de la gravitación; gravedad no introducida aún en la por eso llamada teoría restringida.

El hecho a considerar ahora es el de aludir Einstein en 1905 a un "espacio vacío" (de materia) donde la luz se mueve siempre a la velocidad definida c, explicando el resultado del experimento de 1897 a raíz de una contracción de longitudes real en la dirección del movimiento, de forma que así se compensaba el efecto de la mayor distancia en la dirección orbital. La rectificación de las dos coordenadas, primera y cuarta de las transformaciones de Galileo, la última por la pérdida de simultaneidad entre relojes debida a las velocidades relativas, en las nuevas transformaciones de Lorentz, da lugar a la formulación tradicional del Principio de Relatividad Especial:

La idea fundamental para la teoría especial de la relatividad es esta: los supuestos (1) la constancia de la velocidad de la luz, y (2) la independencia de las leyes, son compatibles si para la conversión de coordenadas y tiempos de un suceso se postulan relaciones de un nuevo tipo («transformación de Lorentz») (...) El principio universal de la STR está contenido en el postulado: las leyes de la fisica son invariantes bajo las transformaciones de Lorentz. ${ }^{20}$

Para nuestro objetivo, sólo decir que la inercia no cambia en su consideración en la STR respecto de la teoría de Newton, al no tenerse en cuenta la gravedad, siendo el espacio sobre el cual se asientan las consideraciones teóricas el denominado espacio de Minkowski, con sus conocidos conos de luz para representar el nuevo estatus del tiempo. El espacio de la STR es tan absoluto e inmóvil como lo era el lugar de todos los lugares al infinito de la teoría clásica: "el espacio tetradimensional de la teoría de la relatividad restringida es absoluto e inmóvil al igual que el espacio de Newton." ${ }^{21}$

Lo único distinto es llamarlo "tetradimensional" con el fin de expresar la supuesta pérdida de simultaneidad de los sucesos distantes en el espacio universal, la eliminación del Tiempo absoluto y la introducción de un tiempo variable para la cuarta coordenada, si a los relojes de medición les afecta la velocidad con la que son movidos y el lugar del campo gravitacional donde se encuentran.

\footnotetext{
${ }^{20}$ Einstein, A. Notas autobiográficas, 55.

${ }^{21}$ Einstein, A. El problema del espacio, del éter y del campo, en la física (1930), 170.
} 
El joven Einstein tenía la pretensión de convertirse en el discípulo aventajado de Ernst Mach y Henri Poincaré, y de ahí su idea inicial de hacer realidad en Física una doctrina relativista pura que eliminara cualquier mención a supuestas entidades metafísicas inobservables. La crítica de Mach y Poincaré al espacio y tiempo absolutos de la teoría de Newton es conocida, y la idea en la mente de Einstein al desarrollar su teoría de la gravitación, como extensión de los resultados obtenidos en la STR, era ofrecer una imagen del mundo donde el espacio y el tiempo absolutos desaparecieran en las sombras y sólo se hiciera alusión a movimientos relativos entre cuerpos. ${ }^{22}$ Incluso pretendió al principio prescindir de todo concepto de "espacio", según insistía Adolf Grümbaun al señalar que si Einstein en su juventud sostenía la proposición: "si toda la materia fuese aniquilada, el espacio métrico desaparecería también", al final de sus días lo que mantenía era algo distinto: "si el campo espacio-tiempo fuera eliminado, no quedaría espacio alguno." ${ }^{23}$

La precisión es de gran importancia para guiarse entre los escritos del físico de Ulm, en cuyas líneas asistimos a frecuentes cambios de posición y parecer sobre determinadas cuestiones, según corresponde a una teoría en gestación, pero que desconciertan al lector posterior. Porque no se parece decir: "según la STR, el espacio-tiempo tiene una existencia independiente de la materia y del campo. (...) Por el contrario, según la GTR, el espacio no tiene existencia peculiar al margen de aquello que llena el espacio. (...) Si suprimimos mentalmente el campo gravitatorio (...) no queda absolutamente nada." ${ }^{24}$

A mantener que si el espacio-tiempo se suprime no queda espacio de fondo, es decir, no hay infinito vacío subyacente a un espacio presumiblemente lleno.

El cambio es fundamental para comprender la obligación de nuestro físico de admitir la versión actual de su teoría, donde el espacio-tiempo se curva ante la presencia de grandes masas de materia y, por tanto, alguna forma de espacio es ontológicamente anterior a la presencia de las masas. Si bien, según la estipulación de A. Grümbaun, no era esa la pretensión original del genio hebreo al exponer su primera teoría de la gravedad, circunstancia susceptible de entenderse mejor si atendemos al experimento mental expuesto en la última obra citada:

Si una caja más pequeña c se halla en reposo relativo en el interior del espacio hueco de otra más grande $\mathrm{C}$, entonces el espacio hueco o cavidad de c es una parte de la cavidad de $\mathrm{C}$,

\footnotetext{
${ }^{22}$ Einstein, A. Consideraciones cosmológicas. Ed. Hawking, 158: "En una teoría de la relatividad consistente no pude haber inercia relativa al "espacio», sino sólo una inercia de unas masas con respecto de otras. Si, por consiguiente, tengo una masa a distancia suficiente de todas las demás masas en el Universo, su inercia debe reducirse a cero."

23 Grümbaun, A. Philosophical problems of space and time, 422. Trad. propia.

${ }^{24}$ Einstein, A. Sobre la teoría de la relatividad especial y general. Apéndice, 138.
} 
y ambas cajas pertenecen al mismo «espacio» que las contiene. La interpretación es, sin embargo, menos sencilla cuando c se mueve respecto a C. Uno se inclina entonces a pensar que c encierra siempre el mismo espacio, pero ocupando una porción variable del espacio C. Entonces es necesario atribuir a cada caja su espacio particular (no concebido como continente) y suponer que estos dos espacios se mueven uno respecto del otro. Antes de percatarnos de esta complicación, el espacio aparece como un medio continente en cuyo seno nadan los objetos corpóreos. Ahora, sin embargo, hay que pensar que existen infinitos espacios que se hallan en mutuo movimiento. El concepto de espacio como algo que existe objetivamente, con independencia de las cosas, es propio ya del pensamiento precientífico, pero no así la idea de un número infinito de espacios en mutuo movimiento. ${ }^{25}$

La cita precedente era necesaria para mostrar la verdadera intención del físico hebreo-alemán, al pretender prescindir por completo del espacio común a los cuerpos del Universo con el objeto de llevar a efecto una teoría relativista coherente.

Si bien la concepción parece amenazar el origen de los cuerpos, al hacer aparecer a las masas y sus campos asociados de gravitación dispersos no se sabe dónde, ni de dónde, de manera que los cuerpos celestes se sustentarían en Nada, es decir, en ningún lugar.

En realidad, creo que la idea le debió surgir de la eliminación de la simultaneidad absoluta entre sucesos distantes, de forma que si los cuerpos y sus campos no coexisten en simultaneidad, o si uno se puede salir de la simultaneidad de existencia con otro por el hecho de alejarse de él a gran velocidad, no hay razón para mantener la idea de un espacio común, cuya presencia aboga expresamente por contener a los cuerpos en su interior en perfecta simultaneidad; si se concibe el espacio en la forma de un todo unido y algo "uno" se define por su simultaneidad de existencia consigo mismo.

No obstante, en la concepción del joven físico se obviaba y se quería evitar precisamente el movimiento inercial respecto al espacio; aun si uno entonces parezca quedarse sin razones tanto para el hecho de lanzar una sonda a Saturno y que llegue allí en un tiempo diferente al de salida en virtud de su velocidad, porque o bien se exigiría la simultaneidad absoluta o bien se viajaría en el tiempo hacia diferentes tiempos, ${ }^{26}$ como para el simple movimiento inercial de irse hacia delante o hacia atrás cuando nuestro móvil acelera o frena, cosa que con las cajas de Einstein o en el barco de Galileo interpretado por Penrose o en el universo plenum de Descartes, no sucedería.

Tal vez pudiera pensarse si las cajas, en el experimento mental de Einstein, deberían interpretarse en la forma de símiles de galaxias y que al cubrir el campo

\footnotetext{
25 Ibid, 122.

${ }^{26}$ Problema tratado en mi escrito: El enigma del tiempo I. La simultaneidad, donde se explican con detalle todas las circunstancias aquí sólo aludidas.
} 
gravitacional de cada galaxia todos los cuerpos inmersos en él, la consecuencia sólo se daría entre galaxias lejanas, que es donde Einstein habría supuesto la inexistencia de un espacio común. Y si bien la apreciación puede ser justa, no es lo que uno infiere de sus primeros escritos, aun si fuese precisamente la hipótesis de Hubble de la expansión del Universo la que parece haber convencido a Einstein de la necesidad de proclamar la existencia del continuo espacio-tiempo. Sea como fuere, tampoco se entendería entonces, si se asume que cada galaxia vive en su propio tiempo, cómo llega la luz de galaxias distantes hasta nosotros, y de igual modo no se entiende cómo podemos seguir la imagen de un cohete cuando se aleja de la Tierra, si por su mayor velocidad pierde al proviso la simultaneidad de existencia con el planeta.

Para nuestro objetivo actual, será conveniente ofrecer el fundamento de donde el sabio europeo obtiene la extensión del Principio de Relatividad a una teoría de la gravitación.

En la STR, la validez del Principio de Relatividad lo es de modo exclusivo para cuerpos inerciales de Galileo, aquellos con movimiento rectilíneo, uniforme e irrotacional respecto al cuerpo de referencia del suceso. Las leyes de la Naturaleza deben ser equivalentes para todos los sistemas inerciales y la base desde donde se entiende que la ley natural expresada en el Principio de Relatividad de Newton ha de ser correcta es la Ley de Inercia, es decir, la definición misma del concepto de movimiento inercial respecto al espacio, según vimos hasta ahora.

Sólo recordar que es sobre el concepto de materia inerte o masa inercial (M) sobre quien se establecen todas las ecuaciones en la física newtoniana y también en la relativista. La masa inercial en la Teoría de la Gravitación Universal se considera igual a la masa gravitacional y por eso las ecuaciones $\mathrm{F}=\mathrm{m} \cdot \mathrm{a}$ y $\mathrm{F}=\mathrm{m} \cdot \mathrm{g}$, son equivalentes, esto es, es la misma la cantidad de materia la afectada por cualquier aceleración mecánica o la provocada por la gravedad. Esta igualdad, a pesar de ser experimental, no estaba explicada, según Einstein, en la teoría clásica.

Los sucesivos Principios de Relatividad no rigen para movimientos acelerados, excepto en el caso de aceleración uniforme con resistencia del medio por su facultad de provocar también una velocidad constante. Sin resistencia, una aceleración uniforme producirá velocidades crecientes indefinidas. El fundamento para dar el paso hacia los movimientos acelerados gravitacionales se explica bien en el libro de 1916. Allí Einstein nos hace entender, continuando con el ejemplo del tren en movimiento respecto al terraplén donde caen dos rayos eléctricos, que si el tren se moviera de modo no uniforme entonces ni el Principio de Relatividad Especial ni el de Galileo resultarían aplicables, al estar pensados en exclusiva para cuerpos inerciales a velocidades constantes. De esta forma, nos dice, pareciera que debemos 
atribuir "una especie de realidad física absoluta al movimiento no uniforme", pero que la inferencia en realidad no es correcta si tenemos en consideración lo siguiente:

El campo gravitatorio, al contrario que el campo eléctrico y magnético, muestra una propiedad sumamente peculiar que es de importancia fundamental. Los cuerpos que se mueven bajo la acción exclusiva del campo gravitatorio experimentan una aceleración que no depende lo más mínimo ni del material ni del estado físico del cuerpo. Un trozo de plomo y un trozo de madera caen exactamente igual en el campo de gravedad (en ausencia de aire) cuando los dejamos caer sin velocidad inicial o con velocidades iniciales iguales. ${ }^{27}$

Y establece que para resultar posible la circunstancia es necesario que la masa gravitacional y la masa inercial de un cuerpo sean iguales. El hecho a su vez supone el fundamento del Principio de Equivalencia entre dos sistemas de coordenadas, uno de ellos dotado de aceleración uniforme respecto del otro. ${ }^{28}$

Como sabemos, fue Robert Boyle en el siglo XVII quien demostró la ley de caída de los graves de Galileo mediante el uso de bombas de vacío en altos recipientes de cristal, de manera que pudo demostrar que todos los cuerpos con independencia de su forma y peso caen en virtud de la gravedad con idéntica velocidad, si son dejados caer desde igual altura y en igual estado de movimiento. El mismo Newton fue testigo de los experimentos, según nos recuerda el siguiente texto de su tratado de Óptica:

"Las pequeñas plumas que caen al aire libre encuentran una resistencia considerable, si bien en un recipiente alto de cristal, vacío de aire, caen con la misma rapidez que el plomo o el oro, según he visto hacer muchas veces." ${ }^{29}$

Para que el hecho en sí sea posible, la masa inercial, sujeto de cualquier tipo de fuerza mecánica o la propia del movimiento inercial donde todos los cuerpos consiguen la misma velocidad constante si son acelerados hasta igual velocidad, ha de resultar igual a la masa gravitacional, sujeto de la aceleración producida por la fuerza de gravedad.

Einstein enuncia por primera vez el Principio de Equivalencia en 1907 y da una explicación más amplia del mismo en el artículo de 1911: Sobre la influencia de la gravitación en la propagación de la luz. Los experimentos del físico húngaro R. Eötvös para probar con exactitud la igualdad de las masas inercial y gravitacional datan de 1890, pero Einstein no los menciona hasta 1913. El experimento aparece más tarde descrito con cierto detalle en el manuscrito de Morgan de 1920. En 1911

\footnotetext{
27 Ibid, 58-60.

${ }_{28}$ Einstein, A. El significado de la relatividad, 75-76.

${ }^{29}$ Newton, I. Óptica, 317. Es muy recomendable ver al respecto el experimento realizado en la superficie de la Luna por los primeros astronautas.
} 
Einstein dice que el Principio de Equivalencia obtiene una explicación satisfactoria a partir del Principio de Relatividad para los sistemas de referencia K y K', si consideramos uno de ellos uniformemente acelerado. La hipótesis implica dejar de hablar de aceleraciones absolutas, si en vez de ello consideramos que el sistema de referencia acelerado lo es con respecto a un campo gravitacional, lo cual conlleva que podemos considerar al otro sistema moviéndose con aceleración uniforme, libre de gravitación.

La deducción exacta debe seguirse en el texto original, si bien es más fácil comprenderlo según el experimento mental descrito en el libro de 1916. En este trabajo de exposición pública, para dotar de interpretación física al Principio de Equivalencia, nuestro físico propone dos versiones del experimento del cajón y la cuerda.

En la primera, nos insta a imaginar un espacioso cajón situado en un amplio espacio vacío. En el centro del techo, por fuera, hay un gancho con una cuerda, y suponemos en un momento determinado a un ser que empieza a tirar de ella con fuerza constante. En el interior hay un hombre a quien el suelo de la habitación le transmite, por presión, la aceleración sufrida por la caja. Su situación, por tanto, será similar a la de un hombre sobre una habitación terrestre, atraído hacia el suelo por el potencial gravitacional del centro de la Tierra. Si cualquiera de los dos soltara un objeto que antes tenía en la mano, caería hacia el suelo en movimiento relativo acelerado. El hombre sujeto a aceleración en el vacío inferirá, aunque esté equivocado, hallarse sometido a un campo gravitatorio bastante constante, en cuyo seno su habitación se halla suspendida sujeta por la cuerda:

"Aun cuando el cajón se halle acelerado respecto al espacio de Galileo considerado, cabe contemplarlo como inmóvil. Tenemos, pues, buenas razones para extender el principio de relatividad a cuerpos de referencia que estén acelerados unos respecto a otros. (...) Esta interpretación descansa en la propiedad fundamental que posee el campo gravitatorio de comunicar a los cuerpos la misma aceleración, o lo que viene a ser lo mismo, en el postulado de la igualdad entre masa inercial y masa gravitacional." 30

La propiedad fundamental del campo de gravitación de acelerar todos los cuerpos por igual con independencia de su masa y forma hace posible aplicar el Principio de Relatividad a los cuerpos acelerados por la gravedad, porque los cuerpos situados en un mismo punto sometidos a igual potencial gravitacional se comportan igual que en el movimiento lineal uniforme. El hombre en el interior del cajón ha de suponer, cuando descubre el gancho y la cuerda tirante, a su móvil en estado de reposo en el campo de gravitación, sujeto por la cuerda, siendo en virtud de ser sólo

$\overline{30}$ Einstein, A. Sobre la teoría de la relatividad especial y general, 61-62. 
él atraído por la gravedad de la fuente la causa de la presión que siente del suelo. Si el cajón no estuviera suspendido en el aire sujeto por la cuerda, caería también hacia la fuente del campo, y el hombre en su interior no sentiría presión alguna del suelo sino que permanecería dentro del cajón en situación de ingravidez, sin mantenerse en pie sobre él pero cayendo a igual velocidad a la del cajón donde se encuentra, en virtud de la igual aceleración provocada por la gravedad sobre todos los cuerpos con independencia de su peso y forma. La anterior, según destacó Einstein y antes de él Galileo Galilei e Isaac Newton, es la propiedad esencial de la gravedad, y merced a ella y las iguales consecuencias en ambos casos, según el resultado del experimento mental, se obtiene la posibilidad de ampliar el Principio de Relatividad a los cuerpos acelerados por un campo gravitacional.

La posibilidad descansa así sobre la igualdad entre masa inercial y gravitacional, que permite considerar a cualquier cuerpo acelerado por un campo gravitacional como si estuviera inmóvil en reposo relativo respecto a una fuente de gravitación. O lo que sería lo mismo: en movimiento lineal uniforme, por cuanto en una determinada órbita todos los objetos se mueven a igual velocidad constante. De esta forma, según muestra el experimento del cajón y la cuerda, desde el cuerpo acelerado por gravedad las leyes de la Naturaleza también deben ser las mismas.

La teoría de la relatividad general debe su creación en primer lugar al hecho experimental de la igualdad numérica que hay entre la masa inerte y el peso de un cuerpo; la mecánica clásica no ofrecía ninguna interpretación de este hecho fundamental. Se llegó a tal interpretación extendiendo el principio de relatividad a sistemas de coordenadas acelerados uno respecto al otro. La introducción de sistemas de coordenadas acelerados respecto a un sistema inercial condiciona la aparición de campos gravitatorios respecto al primer sistema. De esto depende que la teoría de la relatividad general, basada en la identidad entre inercia y peso, proporcione una teoría del campo gravitacional. ${ }^{31}$

En la segunda versión del experimento del cajón suspendido, una página después del anterior, Einstein ofrece aún una mejor interpretación física, y nos hace ver que el mismo efecto se produce en el caso de acelerar el cajón en el espacio vacío donde una cuerda tira de un objeto colgado del techo produciendo su tensión, y en el de considerar al cajón en reposo relativo a la superficie de la Tierra. En la primera imagen, es la masa inerte la sujeta a la acción de la fuerza mecánica, mientras en la segunda es la masa gravitacional la sujeta a la acción de la gravedad de la fuente. Por esta razón es posible extender el Principio de Relatividad a cuerpos acelerados por la gravedad:

31 Einstein, A. Sobre la teoría de la relatividad (1921). En Mi visión del mundo, 149. 
"En este ejemplo vemos que la extensión del principio de relatividad pone de manifiesto la necesidad del postulado de la igualdad entre masa inercial y gravitatoria. Con lo cual hemos logrado una interpretación física de este postulado.”

Ahora bien, resulta prioritario ser conscientes de cómo el Principio de Relatividad va pasando del sistema privilegiado en reposo absoluto respecto al espacio, primero a los sistemas de referencia de Galileo en el movimiento inercial puro newtoniano, luego a la STR para mantener el Principio de Constancia de la velocidad de la luz, y finalmente a la GTR para los cuerpos en movimiento acelerado por los campos gravitacionales. La base de la extensión del Principio en todos los casos se sustenta en la igualdad de comportamiento de los cuerpos en el reposo y a velocidad constante. En la STR a raíz de las transformaciones de Lorentz, y en la GTR en virtud de la propiedad fundamental de la gravedad de acelerar todos los cuerpos por igual en el mismo punto.

Si el Principio de Relatividad alcanza a resultar válido para el fenómeno gravitatorio es porque en un sistema de referencia dado los diferentes objetos son acelerados a la misma velocidad, de manera que la situación es similar a la que acontece en el movimiento inercial sin aceleración respecto al espacio. En ambos casos, los objetos en el interior de una habitación o en los alrededores de un planeta en movimiento mantienen todos la misma velocidad uniforme, si bien las causas del hecho en sí sean distintas para los dos sucesos. En el caso del movimiento inercial puro, los distintos cuerpos mantienen la misma velocidad uniforme porque sobre ninguno de ellos actúa fuerza alguna, mientras en el caso del movimiento de caída libre hacia la fuente o en el movimiento orbital, los cuerpos en un mismo punto son acelerados por separado a igual velocidad constante.

De este modo, dado que en la GTR Einstein puede llamar sistema de referencia inercial a los cuerpos acelerados por la gravedad, si se mueven a velocidad constante respecto de su fuente, parece evitar que la extensión progresiva del Principio de Relatividad desde su formulación en la Física clásica hasta la GTR, pasando por la STR, penda en última instancia del concepto reposo absoluto respecto al espacio.

Prescindir del último concepto era importante para él, porque si a los relojes les afecta la velocidad y la gravedad, un observador en reposo absoluto y alejado de toda fuente de gravitación debería, en pura teoría, registrar la verdadera medida y cadencia del tiempo lineal; de cuyo transcurso inalterable los distintos ritmos de frecuencia de los segunderos de los relojes en movimiento, o sometidos a campos gravitacionales, sólo supondrían diferentes subdivisiones de una misma secuencia de instantes.

Según hemos apreciado en la exposición, Einstein no cesa de hablar de "aceleración” cuando se refiere al movimiento propiciado por la gravitación. Él lo expresa 
claramente en la misma obra: "Los cuerpos que se mueven bajo la acción exclusiva del campo gravitatorio experimentan una aceleración que no depende lo más mínimo ni del material ni del estado físico del cuerpo." ${ }^{32} \mathrm{O}$ de otro modo, pero con igual significado en apariencia, al explicar el sentido físico de los tensores: "El campo gravitatorio transfiere energía y momento a la materia por el hecho de ejercer fuerzas sobre ella, y le da energía." ${ }^{33} \mathrm{O}$ en parecida forma en El fundamento de la GTR: "Este segundo término (de la ecuación bajo explicación) es una expresión para el momento, y para la energía, transferidos por unidad de volumen y unidad de tiempo desde el campo gravitatorio a la materia." ${ }^{34}$ Expresiones cuyo cabal significado parece implicar que el campo de gravedad acelera los cuerpos orbitales, luego éstos no se moverían por mera inercia en el espacio curvo; si bien la teoría original no era excesivamente clara al respecto.

No obstante, en el movimiento de caída libre hacia la fuente no parece posible decir lo mismo, según la siguiente descripción fundamental de la misma obra:

En las proximidades inmediatas de un observador que cae libremente en un campo gravitatorio no existe campo gravitatorio. Por lo tanto, podemos siempre considerar, como Galileo, una región infinitamente pequeña del espacio-tiempo, pues tal región será un sistema inercial... respecto del cual debemos considerar válidas las leyes de la STR. ${ }^{35}$

$\mathrm{Al}$ ser en las regiones infinitesimales donde se cumplen las anteriores leyes de la STR para el movimiento de la luz, precisamente porque pueden concebirse no curvadas si el ámbito de la curvatura es grande, según acontece en la teoría de superficies de Gauss y Riemann. El hecho quiere expresamente decir que el cuerpo cayente, si para él no hay campo gravitatorio en sus inmediaciones, cae por obligación hacia el centro de la curvatura en el interior de la fuente en caída libre. Y aquí, en teoría, no hay aceleración, al ser un movimiento inercial. Por eso decía antes que en el modelo no parece cumplirse la ley de Newton del aumento de la aceleración con el cuadrado de la distancia hacia la fuente: $g=G \cdot M / S^{2}$. Por esta razón, Einstein se ve obligado a seguir las estipulaciones de Ernst Mach respecto de la inercia, y según el físico austriaco la inercia, si no puede serlo respecto del espacio absoluto, ha de serlo respecto del resto de masas del Universo:

"Las masas inertes actúan las unas sobre las otras. (...) La inercia de un cuerpo debe aumentar cuando se acumulan a su alrededor masas ponderables. Un cuerpo debe estar sometido a la acción de una fuerza aceleradora cuando las masas próxi-

\footnotetext{
32 Ibid, 59-60.

33 Einstein, A. El significado de la relatividad, 105.

${ }^{34}$ Einstein, A. El fundamento de la Teoría General de la Relatividad. Ed. Hawking, 126.

35 Ibid, 81-82.
} 
mas se aceleran y, en realidad, dicha fuerza debe tener el mismo sentido que la aceleración." 36

Con la operación se salva el escollo, al convertir la inercia en movimiento acelerado, causado por una nueva especie de fuerza aceleradora en sustitución de la original fuerza de gravedad newtoniana. Porque aquí no se trata de una fuerza inercial ficticia o aparente, sino de un efecto pretendidamente real de una masa sobre otra, un efecto al que califican de inercial. Si bien no deja de ser una hipótesis sorprendente, si en ausencia de transmisión de energía entre cuerpos, uno se acelera cuando se acelera el otro, esto es, recibe inercia por una especie de acción a distancia; precisamente la consecuencia que todos los autores posteriores quisieron evitar de la teoría de Newton, aun si él mismo la negó, reconociendo tan sólo que no sabía cómo se producía la aceleración gravitacional. De ahí las estipulaciones de Albert Einstein cuando decía siempre que la energía contenida en la materia produce el campo gravitatorio, y el campo posee en sí mismo su propia densidad de energía, ${ }^{37}$ transmitida a su vez a la materia bajo el efecto de la gravedad. Por este camino la teoría newtoniana se transforma en el nuevo pensamiento de la curvatura del espacio, una concepción donde "el campo ocupa el lugar de la fuerza." 38

Si unimos lo precedente al constante hablar de la «aceleración» sufrida por los objetos sometidos al campo gravitacional, nos parecerá ser la densidad de energía del campo curvo la causa de la aceleración, incluso también en el movimiento de caída, de forma que la fuerza aceleradora sería esta propiedad del campo de transmitir energía a los cuerpos. No obstante, otras expresiones manifiestan la existencia de cierto "transporte de inercia" responsable de provocar movimiento inercial: "Si la teoría está de acuerdo con los hechos, entonces la radiación transporta inercia entre cuerpos emisores y absorbentes." ${ }^{39}$ Si bien aquí no parece estar hablando de ondulaciones gravitacionales como medio para alimentar la densidad de energía del campo, sino de la disminución de "la energía cinética de un cuerpo (...) como resultado de la transmisión de luz."

El concepto de "transporte de inercia", en orden a continuar las especulaciones de E. Mach: "la afirmación de E. Mach sobre que «la aceleración relativa al espacio absoluto de Newton sólo se entiende propiamente cuando es vista como aceleración relativa a la única masa significativa donde realmente está, las estrellas distantes.» Acorde a esto, el principio de Mach: la inercia aquí surge de la masa allí." ${ }^{40}$ No es un

\footnotetext{
36 Ibid, 124.

37 Einstein, A. El significado de la Relatividad, 105.

38 Einstein, A. Física y Realidad (1936). Ed. Sánchez Ron, 261.

39 Einstein, A. ¿Depende la inercia de un cuerpo de su contenido de energía? (1905) Ed. Hawking, 55.

${ }^{40}$ Ciufolini, I. y Wheeler, J.A. Gravitation and Inertia, 1. Trad. Propia.
} 
problema del todo resuelto en el interior de la teoría, según leemos en los últimos autores citados, y no está lejos, según reconocen también en cierto momento, de la idea de acción a distancia. ${ }^{41}$

Una mejor explicación, tomada del mismo libro, parece ser la siguiente: primero se dice: "en la geometrodinámica de Einstein las propiedades de la inercia local son expresadas a través del tensor métrico $\mathrm{g}_{\mu v}$ " $\mathrm{Y}$ aquí, en un sistema estelar, la inercia es, en consecuencia, un efecto de la curvatura en cada punto orbital. Pero a su vez: "la interpretación de la inercia en la GTR: la geometría del espacio-tiempo y, por tanto, la inercia local en el sentido de Sistemas Locales Inerciales de cada evento a lo largo de la línea de universo de cada partícula de test, son determinadas por la distribución y flujo de energía a lo largo de todo el espacio.” ‘2 Una idea cuyo significado ha de querer decir que la posible curvatura que pudieran provocar masas distantes sobre el espacio aquí, también influye en el movimiento inercial, según acontece con las elipses planetarias en nuestro sistema influidas por la presencia de masas cercanas. A pesar de ello, los autores también parecían haber aceptado el transporte de inercia vía una componente radiativa de la fuerza gravitacional a la velocidad de la luz. ${ }^{43}$

Según se aprecia, el origen de la inercia en la GTR dista de estar plenamente fundamentado, si bien la mejor expresión de la idea es la expresada al final del libro:

La masa-energía dice al espacio-tiempo cómo curvarse y el espacio-tiempo dice a la masa cómo moverse... La masa-energía allí (y aquí) curva el espacio allí (y aquí), y el espacio allí tiene que unirse con uniformidad al espacio en todas partes y el espacio en todas partes al espacio aquí... Por tanto, la masa-energía allí gobierna la inercia aquí. ${ }^{44}$

Dejando de lado por el momento la cuestión de la estricta teoría original de Einstein, las versiones posteriores alabaron la eliminación del carácter de fuerza para la gravedad, si la fuerza ya no reside en la fuente emisora, según sucedía en la teoría de Newton:

En la concepción de la gravedad de Einstein hay dos ideas fundamentales. La primera es la de flotación libre. La segunda es la de curvatura del espacio-tiempo... Cada masa sigue su estado natural de movimiento, la flotación libre, a menos sea desviada por una fuerza eléctrica o elástica... La fuerza que actúa sobre nuestros pies no es de carácter gravitacional. Su origen está en la física del estado sólido y en la elasticidad de la materia... ¡La "gravedad» es una ilusión!... ¡Como primer paso para acercarse a la gravedad, Einstein se deshizo de la

\footnotetext{
41 Ibid, 388-393.

42 Ibid, 395.

43 Ibid, 393.

44 Ibid, 399.
} 
gravedad!... De nadie más que del propio espacio recibirán los objetos sus órdenes principales de movimiento. ${ }^{45}$

Punto donde tiene su lugar el concepto de agujero negro o radio de Schwarzschild, por cuyo medio se calculan los grados de curvatura producidos por cada una de las masas. En realidad, el concepto de black hole surge de las investigaciones teóricas del físico alemán Max Planck, cuando combinaba los contenidos dimensionales de las tres principales constantes universales: $\mathrm{c}, \mathrm{G}$ y h, para obtener unidades naturales de masa, longitud, tiempo, energía, fuerza o carga. Las Unidades Naturales, en tanto parecen describir formas de límites entre magnitudes mediadas por la velocidad de la luz, suscitan por sí mismas el concepto de agujero negro en su máxima expresión, que gracias a la ecuación de Schwarzschild ayudan a convertir la masa de cualquier cuerpo estelar en una longitud o radio mínimo. Si se supone un black hole en el centro de estrellas y planetas, desde sus magnitudes se calcula la curvatura interna a la masa y la externa del campo provocadas por la presencia de la fuente:

"La geometría del espacio-tiempo que rodea la Tierra y el Sol, las estrellas de neutrones y los agujeros negros, y cualquier otro centro de atracción que tenga simetría esférica. (...) La masa del Sol, en unidades convencionales es 1'99 x $10^{30}$ $\mathrm{kg}$. Esto supone 1.476 metros en la unidad geométrica de masa que Einstein nos enseñó a usar. (...) Es también la mitad de la reducida circunferencia que tendría el Sol si estuviera colapsado en un agujero negro. (...) Brevemente, donde hay masa la curvatura es contractiva. Donde no hay masa, la curvatura no es contractiva." 46

Lo que coadyuva a explicar por qué la ecuación de Newton de la aceleración centrípeta funciona para los períodos orbitales pero no para la rotación, si se entiende que la sola curvatura donde hay masa pueda ser contractiva y presione hacia su centro las unidades atómicas componentes de la estrella, sin presencia de fuerza alguna.

Luego con la ayuda del último concepto tenemos el modelo vigente en la GTR, cuya representación nos plantea de inmediato una serie importante de dudas.

\section{Conclusión.}

He mostrado Cómo el Verdadero fUndAMENTo de las teorías físicas se sustenta en la representación mental del fenómeno implicado, prescribiendo las características que ha de tener su imagen coherente para estar de acuerdo con los hechos expe-

\footnotetext{
45 Wheeler, J.A. Un viaje por la gravedad y el espacio-tiempo, 12-23.

46 Ibid, $87-88$ y 123.
} 
rimentales. Lo he denominado en otros lugares Lógica de la Representación, uno de cuyos mejores ejemplos es entender la expresión matemática de la teoría de Einstein procedente en última instancia de su intuición acerca de cómo podría explicarse en imagen el fenómeno gravitacional. De ahí la razón de por qué el físico bávaro mantuviera que en su proceso de pensamiento lo esencial era la imaginación:

"Las palabras del lenguaje no parecen desempeñar papel alguno en mi mecanismo de pensamiento. Las entidades psíquicas que parecen servir como elementos en el pensamiento son determinados signos e imágenes más o menos claras que pueden reproducirse y combinarse voluntariamente. Existe, desde luego, cierta conexión entre estos elementos y los conceptos lógicos relevantes. También es evidente que el deseo de llegar finalmente a conceptos conectados de forma lógica es la base emocional de este juego..." ${ }^{47}$

Porque a pesar de afirmar muchos autores, véase R. Feynman o Cohen-Tannoudji o A. Pais, el exclusivo contenido sólo formal de la GTR en su expresión matemática, sin modelo representativo definido, resulta evidente haber sido la imagen de la curvatura, bien del campo gravitacional producido por la masa material, bien del éter curvado por la presencia de los cuerpos, la idea directriz de la teoría de la gravitación de Einstein.

El pensamiento puro muestra así su capacidad para desvelar la verdadera Realidad mediante juicios sintéticos a priori sobre lo posible y lo imposible, si seguimos las consecuencias lógicas de las diversas hipótesis. Por todo ello, y sin negar nosotros en modo alguno la idea de la curvatura, sí es cierto que la Lógica de la Representación de las teorías de la gravedad da lugar al siguiente racimo de dudas:

$1^{\text {a }}$.El modelo descrito de la GTR elimina la aceleración gravitacional g propia de la teoría de Newton y la sustituye por el potencial gravitacional $\Phi$ en cada punto orbital, pasando de un campo escalar a uno tensorial, donde el potencial denota los grados de curvatura y la densidad del campo, pero que en el movimiento de flotación libre no parece tener influencia previsible, si tan recta y homogénea es una distancia en un espacio cúbico y en uno curvado durante una caída hacia el centro del sistema. Y el movimiento de caída libre parece un deber considerarlo inercial, al haberse eliminado la presencia de fuerzas, según lo sugieren las versiones posteriores.

\footnotetext{
${ }^{47}$ Citado en A. Damasio: El error de Descartes, 132. Recogido a su vez del libro de J. Hadamard: The psichology of invention in the mathematical field. (1945) Sin ofrecer su lugar original. Si bien la mayoría de filósofos no podríamos estar totalmente de acuerdo con el esquema defendido por Damasio, al existir conceptos sin representación imaginativa sobre los cuales también podemos pensar; si bien Damasio extiende el nombre de "imágenes" para abarcar también la forma de las palabras.
} 
Si se pensara, según usualmente lo hacen diversas presentaciones de la teoría, que el cuerpo orbita solamente por inercia, sin aceleración, ante la curvatura del espacio; entonces la inercia en la orbitación y en la caída libre serían diferentes, si el cuerpo cayente realmente se acelera según prescribe la ley del cuadrado de los tiempos y se hacía patente cuando veíamos acelerarse la masa cercana por el hecho de acelerarse a su vez la fuente. Así, en el movimiento orbital habría verdadera inercia con respecto al espacio o campo de gravedad, aun si el campo está curvado y hablemos con Galileo de inercia circular, mientras en la caída libre habría inercia con aceleración; si la idea resulta admisible una vez aceptada la presencia del continuo espacio-tiempo, respecto de quien debería darse la inercia y no respecto de las diferentes masas. Si no, según la GTR, habría dos inercias en el ejemplo de Galileo del cuerpo que sube y luego cae, una sin aceleración hacia arriba, que por la sola tendencia hacia el centro de curvatura se iría deteniendo, y otra acelerada hacia el centro de la esfera.

Para comprobar por qué no puede haber aceleración durante una caída hacia el centro de un sistema en curvatura, debemos entender primero que tan recta y homogénea es una distancia en un espacio cúbico y en uno curvado esféricamente ante un movimiento hacia el centro, si una esfera se inscribe en un cubo. Para entenderlo, juguemos al juego de Einstein e imaginemos una gran región de espacio cúbico inmóvil, vacía de influencias gravitacionales y, por tanto, sin curvatura, donde introducimos una gran masa de materia en condiciones de producir en el interior del gran espacio, no en todo el espacio, la forma esférica de la curvatura. Si un objeto viene a velocidad uniforme inercial desde el interior del gran espacio liso y se dirige justo hacia el centro de la esfera, pronto se ve que el observador elegido, cuando entra en la curvatura perfecta producida por la presencia de la gran masa, no notará cambio alguno en sus condiciones y seguirá con la misma velocidad que traía hacia el centro, siempre que el espacio no se presente contracto. En la imagen, si ya venía con dirección hacia el centro, no "caerá" debido a entrar en la esfera y seguirá su trayectoria inercial hacia el centro con la misma velocidad anterior. No habrá lugar para una aceleración sin presencia de fuerzas. Sólo si entrara en sentido oblicuo no dirigido hacia al centro, sería atrapado por el espacio curvo y acabaría por caer hacia la fuente o se convertiría en un cometa, pero sin aceleración. El objeto central representaría un foco de atracción pero sin ejercer fuerzas, según lo quieren las versiones posteriores. No obstante, Einstein utiliza la constante de gravitación universal G en sus ecuaciones de campo, y el contenido dimensional de $\mathrm{G}$ relaciona de manera 
inequívoca la densidad de materia con una aceleración. Un reto que parece, por tanto, irresoluble por medios exclusivamente geométricos. ${ }^{48}$

$2^{\text {a }}$. Si el principal problema de Isaac Newton con su propia teoría era hacer residir todo el poder de la fuerza gravitacional en el punto central de cada masa estelar, ahora la GTR supone en el interior de estrellas y planetas una tendencia hacia el colapso gravitacional, pero que debe ser de un objeto en algún sentido físico y real, si desde sus magnitudes se calculan los grados de curvatura. No obstante, la longitud del radio de Schwarzschild se obtiene mediante la masa completa de un cuerpo compuesto de átomos, y si consultamos a una autoridad en la materia, según lo es Steven Weinberg, leemos: "Debería enfatizarse inmediatamente que no hay singularidad de Schwarzschild en el campo gravitacional de ningún objeto conocido en el Universo, (...) la solución completa de la ecuación de Einstein dentro de una estrella no exhibe la singularidad de Schwarzschild ni ninguna otra. (...) La singularidad de Schwarzschild no parece tener mucha relevancia en el mundo real." 49

$3^{\text {a }}$. Aun si aceptáramos con un gran acto de fe la presencia real del black hole en el centro de cada esfera celeste en la forma de tendencia hacia el colapso gravitacional, y también la inercia aceleradora respecto de la masa, explicada por medio de la fuerza aparente medida por el observador no inercial de un sistema en rotación, en vez de la inercia clásica respecto al espacio, una vez admitida la presencia de un lugar común denominado continuo espacio-tiem-

${ }^{48}$ La contracción del espacio ha de estar en relación con la rotación de los cuerpos celestes, luego puede deberse al efecto del movimiento rotacional sobre el éter en forma de ondulaciones. Se sigue de la relación: tiempo de rotación de la estrella $\cdot \mathrm{c}=$ diámetro del sistema estelar, de donde si la energía es mayor, el período de rotación es menor y menor también la extensión del Sistema Estelar. El contenido dimensional de G es m3 / kg · s2, según surge de la ecuación de la gravitación universal. Pero este contenido se divide con evidencia en dos partes: (m2 / $\mathrm{kg})(\mathrm{m} / \mathrm{s} 2)$, de donde se deduce la ecuación de la aceleración gravitacional: $\mathrm{g}=\mathrm{G} \cdot \mathrm{M} / \mathrm{S} 2$. Porque la gravedad es eso, la aceleración contraria al intento de salir hacia el espacio desde el planeta.

${ }^{49}$ Weinberg, S. Gravitation and Cosmology, 207. Trad. propia. Una posición en clara oposición a la ortodoxa einsteniana, seguida por la mayoría de autores. El concepto de radio de Schwarzschild es equivalente al de agujero negro y se caracteriza por no dejar escapar la luz de él, de ahí su nombre. En realidad es el resultado de una deducción puramente matemática en el interior del sistema de ecuaciones de la Física. Las magnitudes de Planck, cuyas fórmulas relacionan las tres constantes universales: c, G y ћ, para dar unidades dimensionales mínimas o máximas de tiempo, masa, energía y distancia, dan lugar a la idea de una mínima longitud esférica donde puede estar contenido un máximo de energía en las condiciones de nuestro Universo. Si ponemos cualquier masa en la ecuación de Schwarzschild, el resultado será un radio mínimo cada vez mayor según aumenta la cantidad de energía y materia desde las magnitudes de Planck. A la pequeña esfera así concebida se reducen todas las relaciones de masa y gravedad de un cuerpo. Si bien habrían de matizarse las palabras de S. Weinberg, porque aun si no hubiera agujeros negros reales en el interior de estrellas y planetas, sí parece probable el origen ancestral de las galaxias en la forma de black holes, según la teoría también de S.W. Hawking. 
po, y sin entrar en referencias más complejas; el modelo, según lo expuse: con la curvatura interior y exterior a estrellas y planetas producida por el mero efecto geométrico de la presencia de la masa en el espacio, la inercia aceleradora hacia el núcleo de la fuente, el campo que contiene energía y la transmite a los cuerpos pero sin transmisión de energía desde la fuente al campo, a no ser se admitieran lo que serían auténticas ondas de gravedad; el modelo, así presentado, no consigue explicar una característica esencial y singular del Universo presente, según lo es el movimiento rotacional de todos los cuerpos celestes. Si el centro de cada estrella o planeta se concibe la causa geométrica de la caída libre de los cuerpos, al suponer el centro de curvatura del sistema, no se quiere admitir una fuerza que los acelere y atraiga hacia sí, y la imagen, así concebida, no puede explicar el movimiento de rotación, porque si el espacio fuese la causa habría de explicarse por qué presenta rotación y por el camino volveríamos a la consideración de una fuerza. Algo debe procurar en origen los movimientos de rotación, según lo leímos antes en una cita de Newton al definir la Vis inertiae: "Con este principio solo, nunca habría movimiento en el mundo. Se requiere otro principio para poner los cuerpos en movimiento."

La GTR es una teoría geométrica pura, según fue denunciado en su momento por los filósofos franceses H. Bergson y E. Meyerson, y no admite transmisión de energía generadora de gravitación entre los diferentes cuerpos, ni desde la fuente al campo, al menos en la exposición de J.A. Wheeler. El modelo es en cierta medida estático, ${ }^{50}$ si la presencia de la masa con su singularidad interna produce, por efecto meramente geométrico, la curvatura, y los satélites orbitan rodando por sus aros. Pero la GTR no consigue explicar así por qué todos los cuerpos celestes presentan movimiento de rotación, si los precisos períodos de rotación los pretenden explicar también por un efecto inercial.

La fe en lo imposible surge de pretender hacerlo sin acudir a una fuerza de gravedad inmanente, debido principalmente al hecho constatado de la rotación cuantiza$d a$, según la describía el siguiente texto de Max Planck:

W. Nerst había sugerido anteriormente que al quanto de energía de una vibración también debe corresponder un quanto de energía de rotación y, por tanto, era de esperar que la energía de rotación de las moléculas de gas desapareciera con la caída de la temperatura. Las

\footnotetext{
50 "El problema del campo gravitacional estático de simetría central ha sido resuelto completamente por Schwarzschild y otros...” Einstein, A. El significado de la Relatividad, 117.
} 
mediciones realizadas por A. Eucken sobre el calor específico del Hidrógeno confirmaron esta conclusión... El hecho de que las rotaciones cuantizadas de las moléculas de gas, según requieren las condiciones cuánticas, realmente existen en la naturaleza, ya no puede ponerse en duda a la vista de los trabajos sobre bandas de absorción en el infrarrojo por N. Bjerrum, E. von Bahr, H. Rubens, G. Hettner y otros, a pesar de no haber sido posible dar una explicación exhaustiva de todos los aspectos de este notable espectro de rotación hasta ahora. ${ }^{51}$

Si la teoría clásica ya relacionó mediante ecuaciones los períodos de rotación de las estrellas y los tiempos orbitales, se sigue que rotación y movimiento orbital se deben al mismo fenómeno: la gravedad. Si los tiempos de rotación y los períodos orbitales están correlacionados por ecuaciones y el movimiento de rotación de los elementos primarios es en sí cuántico, según lo acusaba Planck, e inmanente al cuerpo en proporción a su densidad de energía, es conclusión obligada que el movimiento de rotación no puede ser sino el efecto de la fuerza de gravedad. Aun si el movimiento orbital, debido a la curvatura, podría no serlo. Todo depende de cómo concebimos la curvatura y de si se estima necesaria la presencia de un proceso de aceleración, bien se halle situado en el campo extenso, bien tenga su origen en la fuente. Teniendo presente que la transmisión de la gravedad a la velocidad de la luz parece un hecho constatado y también que siempre debemos concebir la gravedad actuando por igual en el universo micro y en el mundo macro. Así se entiende por qué GTR y Teoría Cuántica no pueden encontrarse.

Fuerza de gravedad responsable entonces de los movimientos rotacionales y de la siguiente descripción del gran físico italiano Galileo Galilei, porque si bien la inercia no se ha de perder con el movimiento voluntario, queda por explicar la atracción con aceleración hacia el centro y, ante todo, ¿por qué los cuerpos siguen la rotación de su fuente, sin ser inercial en ningún sentido el movimiento de rotación?

"E quello che mantiene inalterato cotal moto ne gli uccelli, è l'aria stessa per la quale e' vanno vagando, la quale, seguitando naturalmente la vertigine della Terra, sí come conduce seco le nugole, cosí porta gli uccelli ed ogn'altra cosa che in essa si ritrovasse pendente." 52

\footnotetext{
51 Planck, M. La génesis y el estado presente de desarrollo de la teoría cuántica. Conferencia Nobel.

52 Galileo. Dialogo sopra i due massimi sistemi del mondo tolemaico e copernicano, 104. Ed esp., p.160.
} 


\section{Referencias Bibliográficas}

Aristóteles. Física. RBA. Barcelona 2007.

Bernard Cohen, I. El nacimiento de una nueva ciencia. Cambridge 1984. Alianza. Madrid 1986

Ciufolini, I. Wheeler, J.A. Gravitation and Inertia. Princeton University Press. New Jersey 1995

Crombie, A.C. Historia de la ciencia 2. De Agustín a Galileo. Oxford 1969. Alianza. Madrid 1996.

Einstein, A. Albert Einstein. Edición de J.M. Sánchez Ron. Crítica. Barcelona 2005

- Sobre la teoría de la relatividad especial y general. Jerusalem 1916. Alianza ed. Madrid 1995.

- Mi visión del mundo. Zurich. Tusquets. Barcelona 2002.

- Notas autobiográficas. Illinois 1949. Alianza ed. Madrid 1992.

- La gran ilusión. Edición de S. Hawking. 2007. Crítica. Barcelona 2008.

- El significado de la relatividad. Espasa Calpe. Madrid 2008.

Galileo Galilei. Diálogo sobre los dos máximos sistemas del mundo: ptolemaico y copernicano. 1630. Alianza. Madrid 1994. Dialogo sopra i due massimi sistemi del mondo tolemaico e copernicano. Edizione Nazionale delle opere di Galileo, vol. VII. R.E. Liber Liber.

- Consideraciones y demostraciones matemáticas sobre dos nuevas ciencias. LEIDEN 1638. Editora Nacional. Madrid 1981

Galison, P.L. Relojes de Einstein, mapas de Poincaré. Los imperios del tiempo. 2003. Crítica. Barcelona 2005

Grünbaum, A. Philosophical problems of space and time. Alfred A. Knopf. N.Y.1963

Newton, I. Principios matemáticos de filosofia natural. 2 vol. Alianza. Madrid 1998.

- Óptica. Alfaguara. Madrid 1977.

Penrose, R. El camino a la realidad. London 2004. Debate. Barcelona 2006 
Planck, M. La génesis y el estado presente de desarrollo de la teoría cuántica. R.E. Nobelprize.org Nobel Media AB 2013

Stachel, J. 1905: Un año milagroso. Princeton 1998. Crítica. Barcelona 2001

WeInberg, S. Gravitation and Cosmology. John Wiley and Sons, Inc. U.S.A. 1972

WheELer, J.A. Un viaje por la gravedad y el espacio-tiempo. N.Y. 1990. Madrid. Alianza 1994

Wheeler, J.A., Misner, Ch. W., Thorne, K.S. Gravitation. W.H. Freeman and Co. U.S.A. 1970

DOI: http://dx.doi.org/10.15366/bp2018.18.022

Bajo Palabra. II Época. No18. Pgs: 421-454 
